\title{
Using Anonymous Connected Vehicle Data to Evaluate Impact of Speed Feedback Displays, Speed Limit Signs and Roadway Features on Interstate Work Zones Speeds
}

\author{
Jijo K. Mathew, Jairaj Desai, Howell Li, Darcy M. Bullock \\ Purdue University, West Lafayette, USA \\ Email:kjijo@purdue.edu, desaij@purdue.edu, howell-li@purdue.edu,darcy@purdue.edu
}

How to cite this paper: Mathew, J.K., Desai, J., Li, H. and Bullock, D.M. (2021) Using Anonymous Connected Vehicle Data to Evaluate Impact of Speed Feedback Displays, Speed Limit Signs and Roadway Features on Interstate Work Zones Speeds. Journal of Transportation Technologies, $11,545-560$.

https://doi.org/10.4236/jtts.2021.114034

Received: August 7, 2021

Accepted: August 30, 2021

Published: September 2, 2021

Copyright $\odot 2021$ by author(s) and Scientific Research Publishing Inc. This work is licensed under the Creative Commons Attribution International License (CC BY 4.0).

http://creativecommons.org/licenses/by/4.0/

\begin{abstract}
Annually, there are over 120,000 crashes in work zones in the United States. High speeds in construction zones are a well-documented risk factor that increases the frequency and severity of crashes. This study used connected vehicle data to evaluate the spatial and temporal impact that regulatory signs, speed feedback displays, and construction site geometry had on vehicle speed. Over 27,000 unique trips over 2 weeks on a 15-mile interstate construction work zone near Lebanon, IN were analyzed. Spatial analysis over a $0.2-\mathrm{mi}$ segment before and after the posted speed limit signs showed that the regulatory signs had no statistical impact on reducing speeds. A before/after analysis was also conducted to study the impact of radar-based speed feedback that displays the motorists' speed on a sign below a regulatory speed limit sign. Results showed a maximum drop in median speeds of approximately $5 \mathrm{mph}$. Speeds greater than $15 \mathrm{mph}$ above the speed limit dropped by $10 \%-15 \%$. The reduction in speeds began approximately 1000 feet ahead of the sign and results were found to be statistically significant. The analysis also revealed that larger speed drops inside the work zone were due to geometric constraints that required additional driver workloads, especially during shoulder width changes and lane shifts. The results from this study will be helpful for agencies to understand driver behavior in the work zones and to identify proper speed limit compliance techniques that significantly reduce driver speeds in and around work zones.
\end{abstract}

\section{Keywords}

Connected Vehicle, Trajectory Data, Speed Limit, Compliance, Work Zones, Construction 


\section{Introduction}

Annually, there are over 120,000 crashes and nearly 800 fatalities in work zones in the United States [1]. More than 120 worker fatalities occur every year in construction work zones [2]. Reducing the frequency and severity of crashes, and the overall amount of congestion in work zones is an important goal for agencies. High speeds in construction zones are a well-documented risk factor that increases the frequency and severity of crashes. There are several speed compliance measures adopted by agencies to limit speeds in work zones including traffic control devices, design alterations and enforcement. Although the impact of various speed compliance techniques and enforcement using spot measurements are well documented, their impact throughout the work zone has been challenging to analyze. The motivation of this paper is to use an anonymous connected vehicle data set that provides a large sample covering all hours of the day to assess the impact of the following on speed:

- Regulatory speed limit signs;

- Speed feedback displays;

- Work zone features such as the change in shoulder width and lane shifts.

\section{Literature Review}

Speed limit compliance in work zones is a major concern for agencies as higher speeds are correlated with the frequency and severity of crashes [3] [4] [5]. There are plenty of studies that evaluate the impact of different speed compliance techniques in work zones including flagging [6], reduced speed limits [7] [8] [9], variable message signs [6] [7] [8] [10] [11], design alterations such as lane merge and lane drops [12] [13] [14], innovative signs [15] [16], automated speed photo enforcement [17] [18] [19] and transverse striping/rumble strips [20] [21] [22]. Several studies have found law enforcement to have the largest impact on speed compliance [7] [23] [24] [25]. Brewer et al. found that in the absence of enforcement, drivers are more likely to drive at their own comfort level, regardless of the posted speed limit [8].

Several studies have also looked at the impact of speed limit signs with speed displays [15] [26] [27] [28] [29]. McCoy et al. studied the effectiveness of the speed display sign on an interstate highway work zone in South Dakota and found that mean approach speeds reduced by $4-5 \mathrm{mph}$ and the percentage of vehicles exceeding the advisory speed limit of $45 \mathrm{mph}$ reduced by $20 \%-40 \%$ [26]. Another study conducted between two work zones on I- 80 found that the speed monitoring displays were effective in lowering the speeds and increasing the uniformity and speed limit compliance [27]. Few studies reported that changeable message signs with radar speeds significantly reduced the speeds in the immediate vicinity of the sign and did not demonstrate any novelty effects [15] [29].

Most of the above studies were conducted using spot speeds and required the 
investment of considerable amount of time and resources for data collection. Very few studies have used connected vehicle data to study the speed limit compliance in work zones [30] [31]. Wasson et al. used segment-based probe data to evaluate the spatial and temporal effect of enforcement on speed compliance in work zones and found that space mean speeds decreased by approximately 5 mph throughout the 12-mi study segment [31]. The above study also found that space mean speeds increased within 30 minutes after the enforcement ended.

\section{Study Scope}

The main objective of this study is to use connected vehicle data to evaluate the speed compliance of different post-mounted speed limit signs and a radar-based speed limit sign with motorist speed feedback display in a work zone (Figure 1). A secondary objective is to identify locations in the work zone with major speed drops and understand the factors that affect the driver behavior at these locations.

The study site is a $15-\mathrm{mi}$ reconstruction project on Interstate I-65 near Lebanon, IN (Figure 2). This study focused on the southbound (SB) direction between mile markers (MM) 153 and MM 138. There are five speed-limit transitions in the work zone as seen in Figure 2, callout i from $70 \mathrm{mph}$ to $55 \mathrm{mph}$, callout ii from 55 to $45 \mathrm{mph}$, callout iii from 45 to $55 \mathrm{mph}$, callout iv from 55 to $45 \mathrm{mph}$ (when flashing) otherwise $70 \mathrm{mph}$ and callout $\mathrm{v}$ where speed limit resumes to $70 \mathrm{mph}$. An additional radar-based speed limit sign with the motorist speed feedback display (Figure 1) was placed near MM 148.5 (callout vi on Figure 2) during the first week of June 2021 to evaluate its impact on speed compliance.

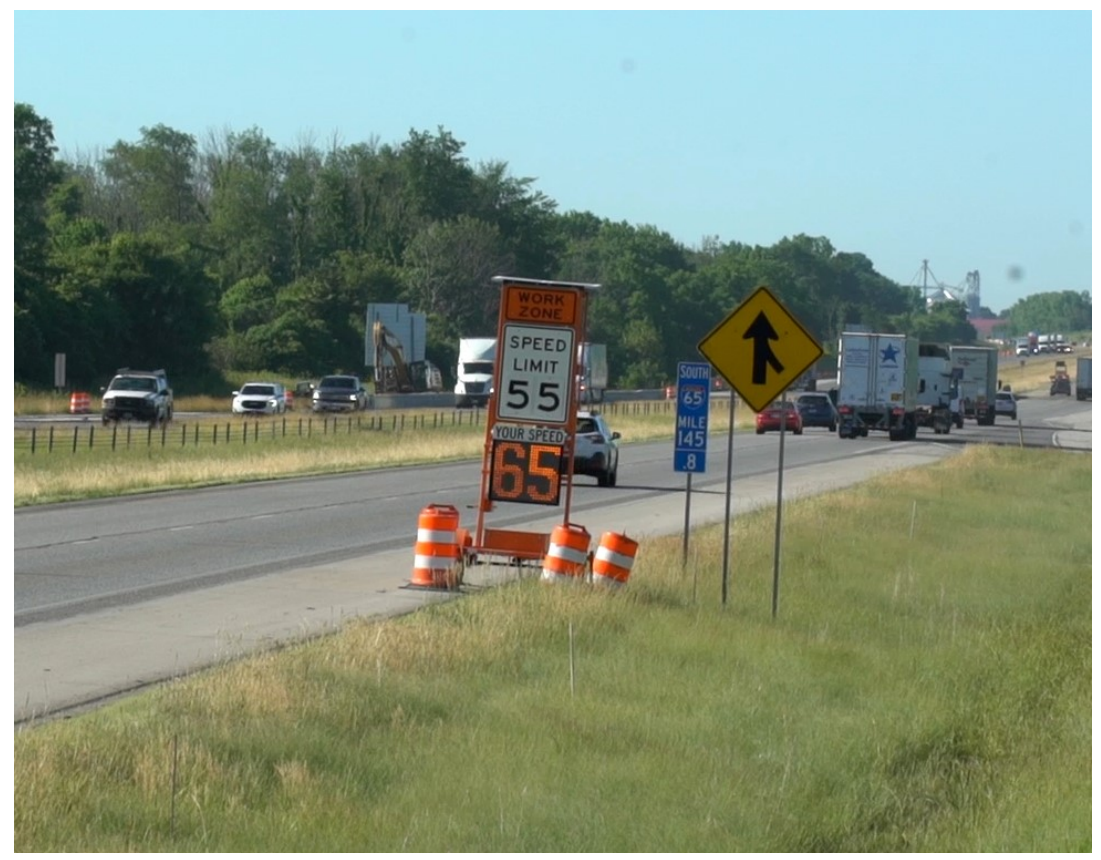

Figure 1. Radar-based speed limit sign with motorist speed feedback. 


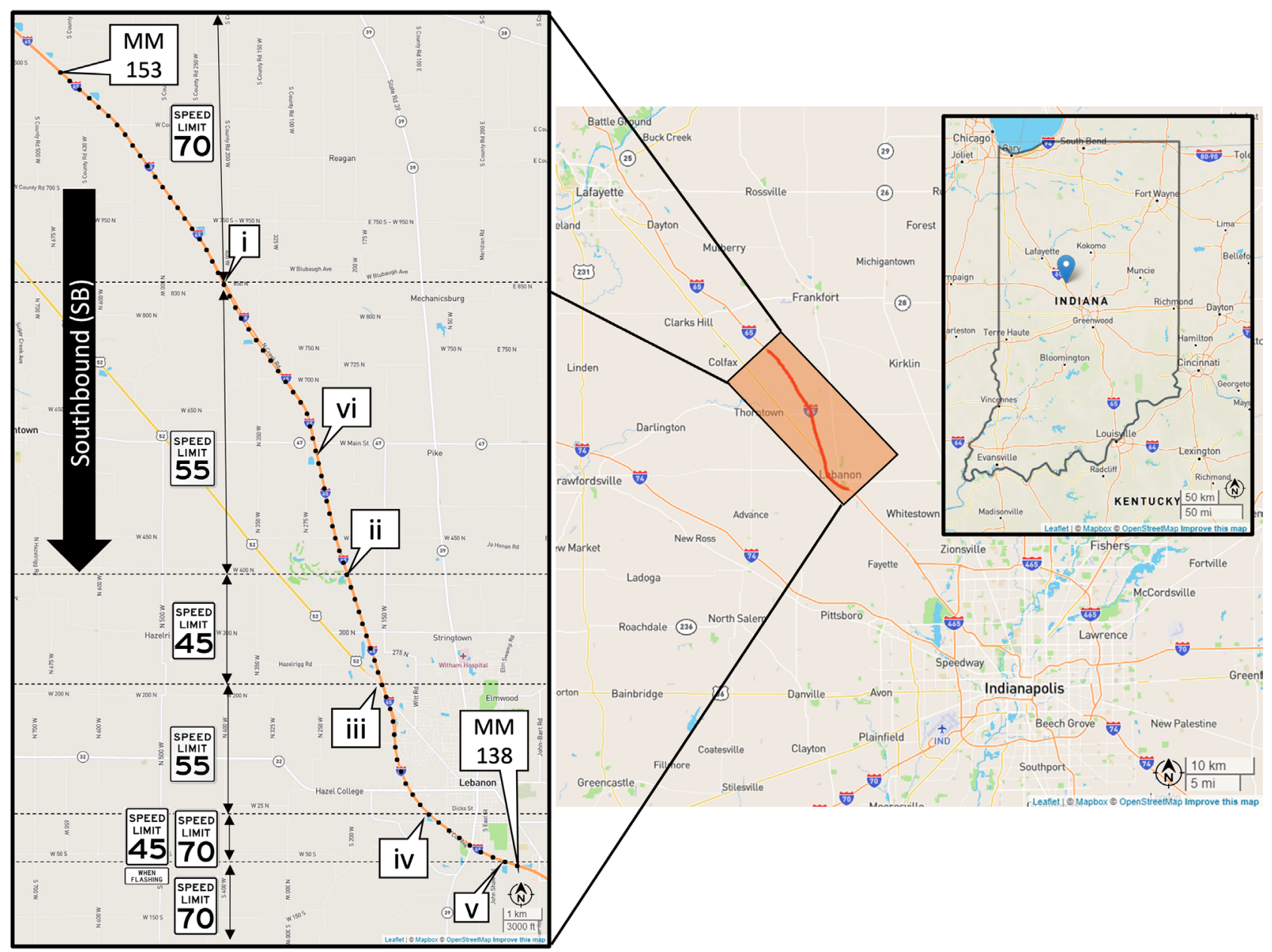

Figure 2. Overview map of work zone and location of speed limit signs.

\section{Connected Vehicle Data}

There are several third-party commercial data providers that aggregate and anonymize original equipment manufacturers (OEM) connected vehicle data to provide high-fidelity vehicle trajectories with reporting intervals of 3 - 5 seconds. This anonymized data consists of a unique trip and data point identifier with geo-positional coordinates, timestamp, speed, heading and ignition status. Indiana ingests over 11 billion anonymized connected vehicle records per month [32] that represents around 4\% penetration [33]. For this study, approximately 4 million data points were extracted over a two-week period (May 25-31, 2021, and June $7-13,2021)$ that corresponded to approximately 27,000 unique trips passing through the study area. To remove any potential bias, congested conditions were discarded from the data set so that free flow conditions could be used for the statistical analysis.

\section{Impact of Posted Speed Limit Signs}

\subsection{Work Zone Configuration}

Figure 3 shows an interquartile range plot or boxplot of the speeds at every 


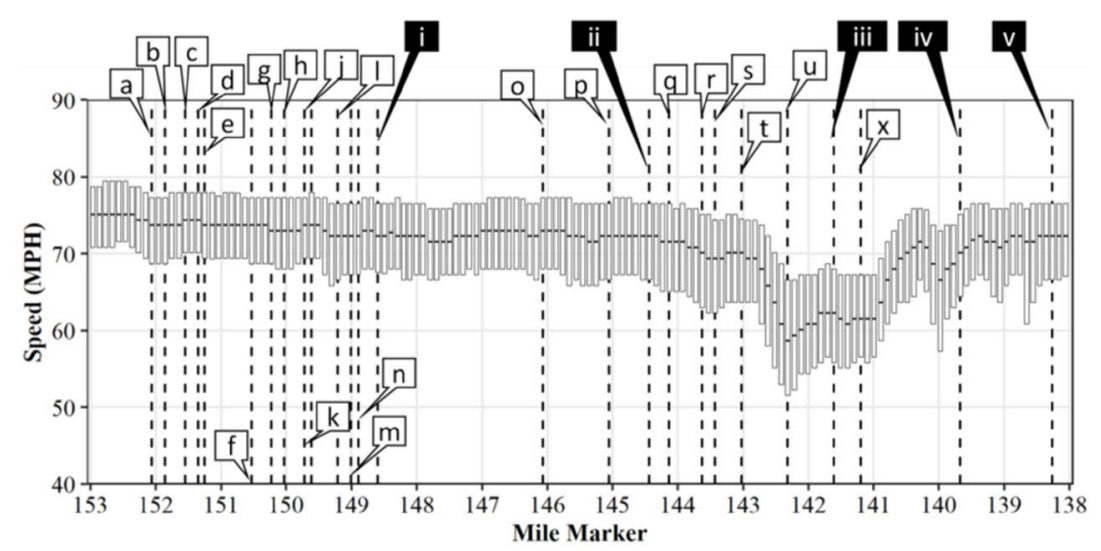

Figure 3. Boxplot of speeds every $0.1-\mathrm{mi}$ with location of road signs.

0.1-mi increment along the work zone for a 1-week period (May 25-31, 2021). The $\mathrm{x}$-axis highlights the southbound mile markers in the direction of travel and $y$-axis highlights the interquartile range of the speeds, with the bottom end representing the $25^{\text {th }}$ percentile speeds, midpoint representing median speed and top end representing the $75^{\text {th }}$ percentile speed. This plot is overlaid with dotted lines illustrating the location of warning and posted speed limit signs placed throughout the work zone. Table 1 shows a list of all the signs and their corresponding miler marker location.

\subsection{Spatial Analysis}

Figure 4(a) shows the same boxplot of speeds from Figure 3, with just the location of posted speed limit signs. Callouts $\mathrm{i}$, ii, iii, iv and $\mathrm{v}$ denotes the location of different speed limit signs posted along the work zone. Callouts $i$ and ii are reduced speed limits from $70 \mathrm{mph}$ to $55 \mathrm{mph}$ and $55 \mathrm{mph}$ to $45 \mathrm{mph}$, respectively. Callouts iii and $\mathrm{v}$ are increased speed limits from $45 \mathrm{mph}$ to $55 \mathrm{mph}$ and $45 \mathrm{mph}$ to $70 \mathrm{mph}$, respectively. Callout iv shows the sign $45 \mathrm{mph}$ when flashing or 70 mph otherwise. As seen, the speed limit signs have little to no impact near the boundary conditions, except when speed limit increases. It is interesting also to note that median speeds were mostly above $70 \mathrm{mph}$ except between callouts ii and iv, where geometric constraints such as lane shifts (callout $\mathrm{q}$ and $\mathrm{x}$ from Figure 3) resulted in lower speeds. Additionally, the lowest $25^{\text {th }}$ percentile of speeds for any 0.1 -mi section was above $50 \mathrm{mph}$, even though posted speed limits were below $45 \mathrm{mph}$ for more than 3 miles.

To evaluate the impact of posted speed limit signs at boundary locations, further spatial analysis within a $0.2-\mathrm{mi}(\sim 1000 \mathrm{ft})$ upstream and downstream of the sign is conducted. Figure 4(b) shows the boundary condition at callout i from Figure 4(a), where the posted speed limit reduces from $70 \mathrm{mph}$ to $55 \mathrm{mph}$. Speed records on a $0.2-\mathrm{mi}$ section before (MM 148.8 - 148.6) and after (MM 148.6 - 148.4) the speed limit sign (MM 148.6) are compared.

Figure 5 illustrates cumulative frequency diagrams (CFDs) comparing the speeds in the before and after section for the five speed-limit transitions (callout $\mathrm{i}$ - 


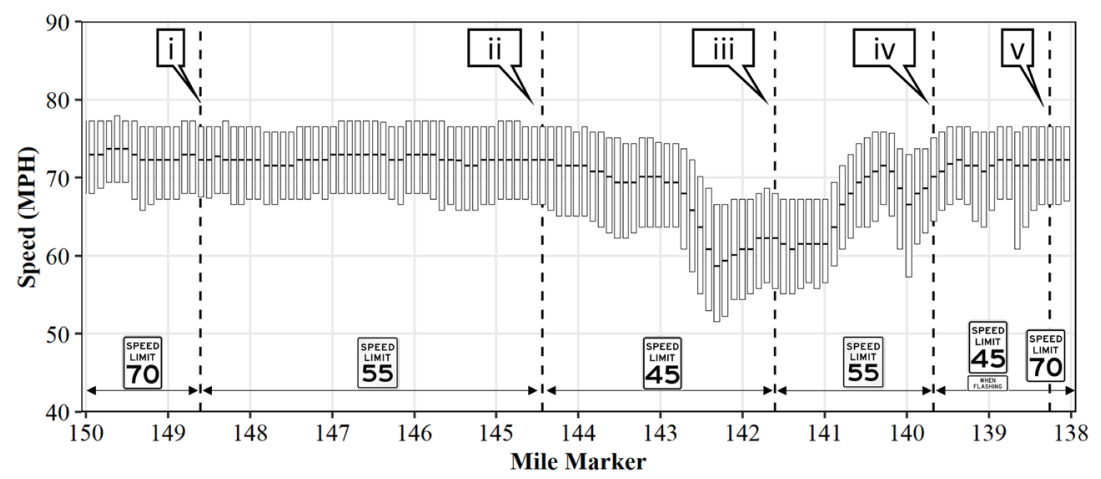

(a)

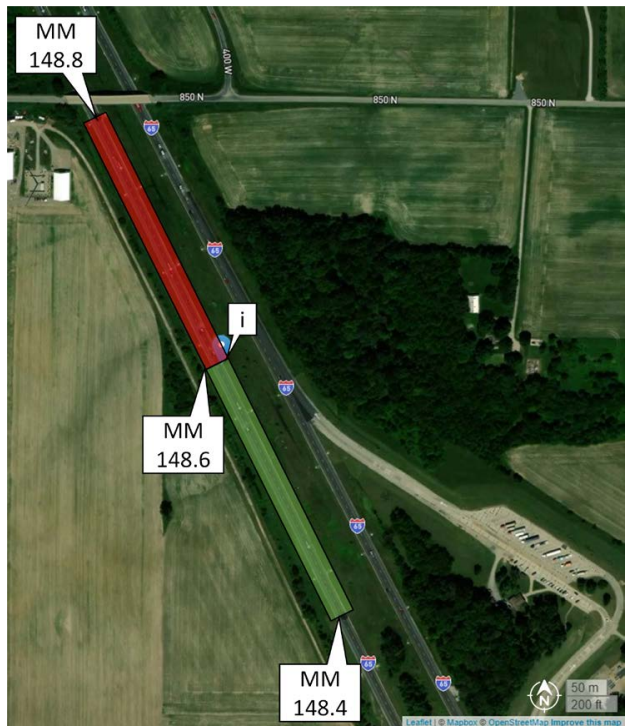

(b)

Figure 4. Spatial analysis of posted speed limit signs. (a) Boxplot of speeds with location of posted speed limit signs; (b) Spatial analysis adjacent to MM 148.6 over a 0.2 -mi $(\sim 1000 \mathrm{ft})$ before and after section from the speed limit sign at callout $\mathrm{i}$.
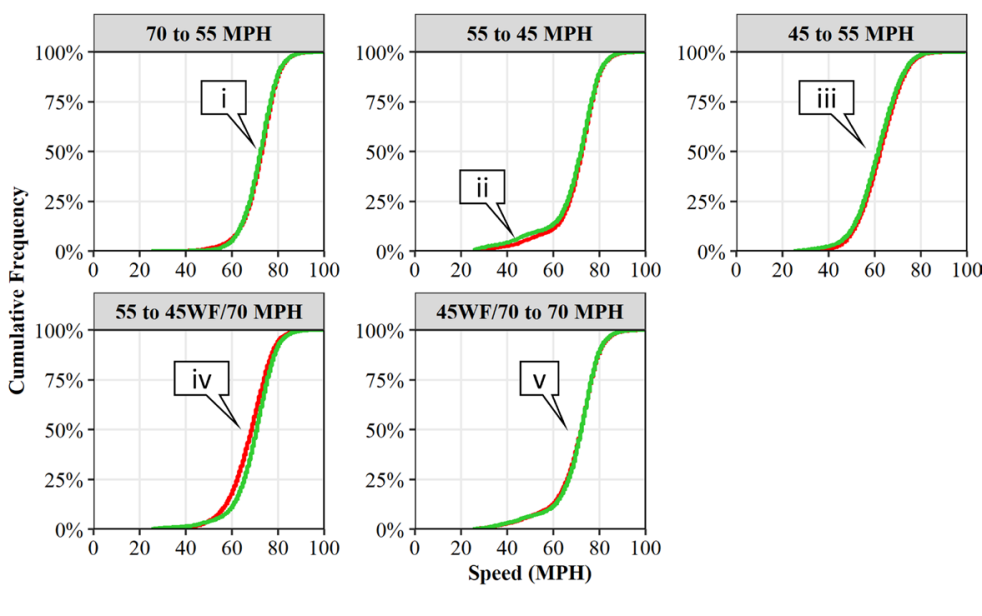

- Before - After

Figure 5. CFDs illustrating distribution of speeds on the $0.2-\mathrm{mi}$ section before and after posted speed limit sign. 
Table 1. Road signs from Figure 3.

\begin{tabular}{|c|c|c|}
\hline Figure 3 Callout & Mile Marker & Road Sign \\
\hline $\mathrm{i}$ & 148.6 & Speed Limit $55 \mathrm{MPH}$ \\
\hline ii & 144.4 & Variable Speed Limit $45 \mathrm{MPH}$ \\
\hline iii & 141.6 & Speed Limit $55 \mathrm{MPH}$ \\
\hline iv & 139.6 & Speed Limit When Flashing $45 \mathrm{MPH}$; Speed Limit $70 \mathrm{MPH}$ \\
\hline $\mathrm{v}$ & 138.2 & Speed Limit $70 \mathrm{MPH}$ \\
\hline a & 152.0 & Road Work Ahead (Variable Message Sign) \\
\hline $\mathrm{b}$ & 151.8 & Speeding Fine \\
\hline c & 151.5 & Road Construction 2 Miles \\
\hline $\mathrm{d}$ & 151.3 & Speeding Fine \\
\hline e & 151.2 & Road Work 2 Miles \\
\hline $\mathrm{f}$ & 150.5 & Road Construction 1 Mile \\
\hline g & 150.2 & Road Work 1 Mile \\
\hline $\mathrm{h}$ & 150.0 & Road Construction 0.5 Miles \\
\hline j & 149.7 & Road Work 0.5 Miles \\
\hline $\mathrm{k}$ & 149.6 & Road Construction Ahead \\
\hline 1 & 149.2 & Road Work Ahead \\
\hline $\mathrm{m}$ & 149.0 & Road Work Ahead (Variable Message Sign) \\
\hline $\mathrm{n}$ & 148.9 & Speed Limit $55 \mathrm{MPH}$ Ahead \\
\hline o & 146.0 & Speed Limit $55 \mathrm{MPH}$ \\
\hline $\mathrm{p}$ & 145.0 & Speed Limit $55 \mathrm{MPH}$ \\
\hline $\mathrm{q}$ & 144.1 & Lane Shift Ahead \\
\hline $\mathrm{r}$ & 143.6 & Speeding Fine \\
\hline$s$ & 143.4 & Road Construction Ahead \\
\hline $\mathrm{t}$ & 143.0 & Lane Shift Ahead \\
\hline $\mathrm{u}$ & 142.3 & Speed Limit When Flashing $45 \mathrm{MPH}$ \\
\hline $\mathrm{x}$ & 141.2 & Lane Shift Ahead \\
\hline
\end{tabular}

v from Figure 4(a)) in the work zone. Overall, none of the reduced speed limit signs (callout $i$ and ii) had any significant impact on reducing speeds.

Median speeds remained around $72 \mathrm{mph}$ after the posted speed limit dropped from $70 \mathrm{mph}$ to $55 \mathrm{mph}$ (callout i). In the second location, where speed limit reduced from $55 \mathrm{mph}$ to $45 \mathrm{mph}$, the observed median speeds also remained around $72 \mathrm{mph}$. Less than $7 \%$ of the speeds were below $45 \mathrm{mph}$ in the after section (callout ii) -an increase of $2 \%$ from the before section. The third location, where speed limit rose from $45 \mathrm{mph}$ to $55 \mathrm{mph}$, also had similar distributions in the before and after section. In contrast to the previous two locations, median speeds for both the sections in this location dropped to $62 \mathrm{mph}$ (callout iii). As seen earlier, this is due to the geometric constraints in this section of the work zone. In location 4, where speed limit increased from 55 to $70 \mathrm{mph}$ (or $45 \mathrm{mph}$ when flashing), the observed speeds in the after section also increased, as ex- 
pected. The median speeds in the after section increased to $70 \mathrm{mph}$, an increase of more than $2 \mathrm{mph}$ compared to the before section (callout iv). The speed distributions for before and after speeds in the final location also did not vary much, possibly because of similar speed limits. However, median speeds for both sections rose to $72 \mathrm{mph}$ (callout $\mathrm{v}$ ).

\section{Impact of Radar-Based Speed Feedback Display with Speed Limit Sign}

Figure 6 shows two boxplots, similar to Figure 4(a), comparing the speeds before (Figure 6(a)) and after (Figure 6(b)) the placement of the radar-based speed feedback display sign with a $55 \mathrm{mph}$ speed limit advisory (referred to as speed feedback display sign from hereafter) (Figure 1). The speed feedback display sign was deployed on June 2, 2021 at MM 145.8 (callout vi). Data was compared between the before period extending from May 25-31, 2021 and the after period extending from June 7-13, 2021. Comparing callout vi on Figure 6(a) and Figure 6(b), there is a clear sharp drop in speeds near the sign during the after period, indicating that the speed feedback display sign had some impact on driver behavior. It is also interesting to note that the speed drops begin a few tenths of a mile ahead of the sign.

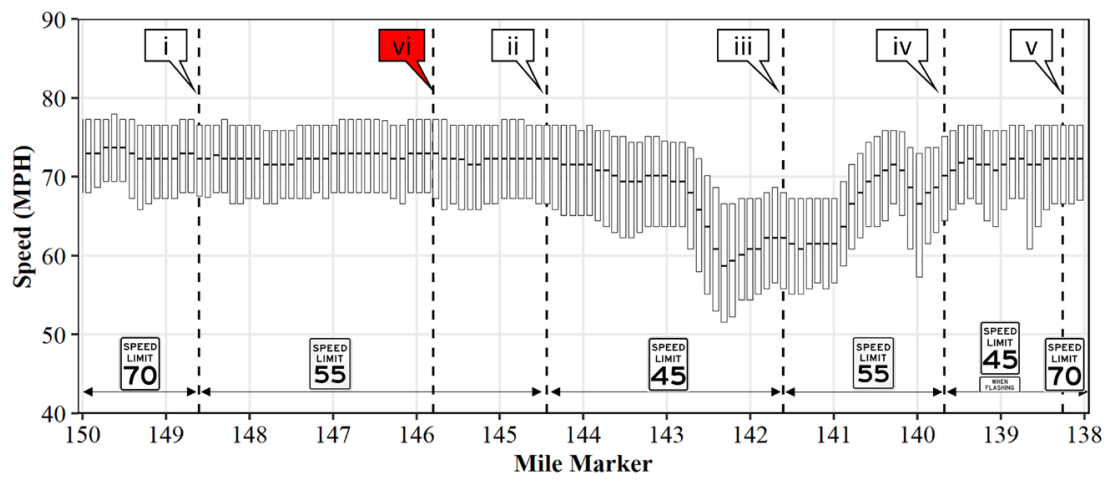

(a)

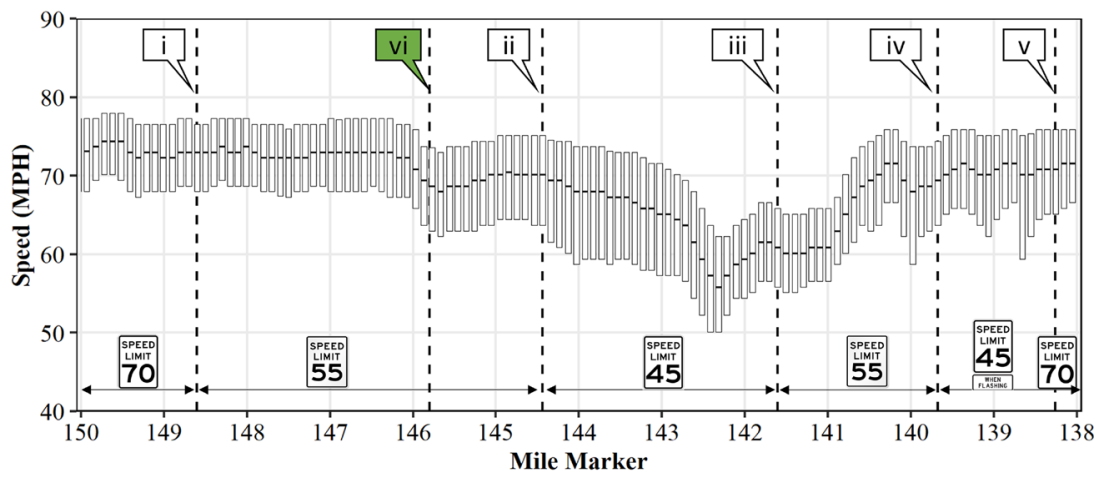

(b)

Figure 6. Boxplots comparing speeds before and after the placement of speed feedback display sign (callout vi). Sign was placed at MM 145.8 on June 2, 2021. (a) Before (May 25-31, 2021); (b) After (June 7-13, 2021). 
To further evaluate the spatial impact, CFDs of speeds are plotted for sections before and after the speed feedback display sign, as shown in Figure 7(a). Each panel represents a $0.1-\mathrm{mi}$ section. Callout $\mathrm{i}$ shows the CFD for the section between MM 145.8 and MM 145.7, where the speed feedback display sign was deployed. As seen, there is no considerable difference in distributions for the panels between MM 146.3 (0.5 mi before the sign) and MM 146.1 ( $0.3 \mathrm{mi}$ before). The reduction in speeds begins around MM 146, approximately $0.2-\mathrm{mi}$ ( 1000 ft) upstream of the sign (callout ii), as shown by the "After" curve that begins to shift slightly towards the left indicating the drop in speeds. This is
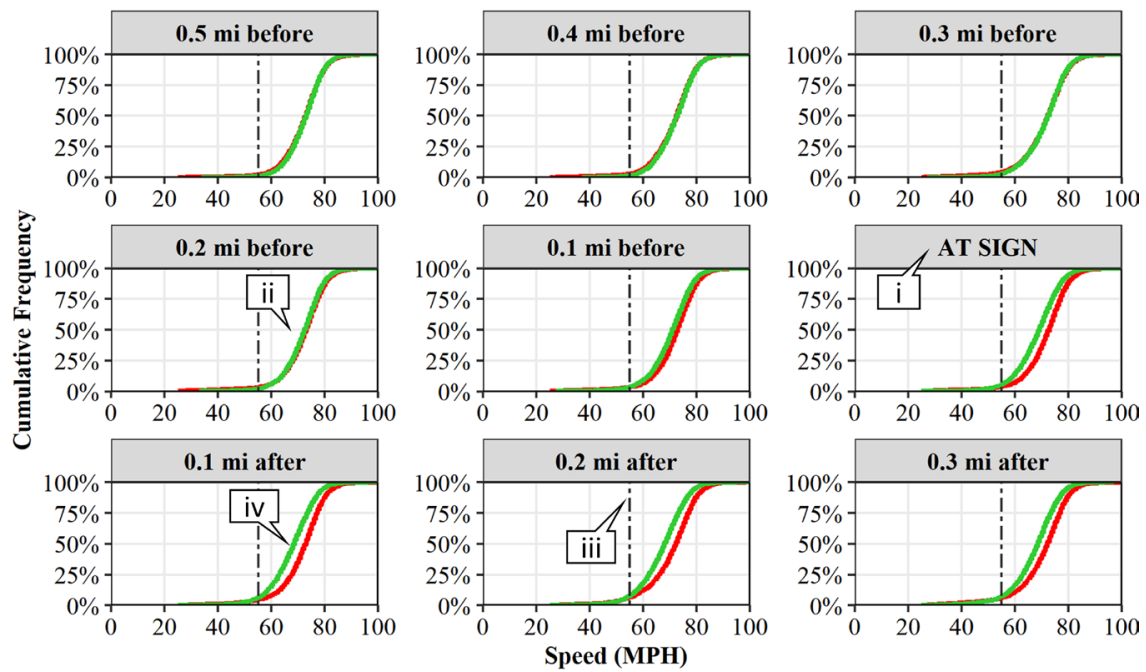

— Before Deployment — After Deployment

(a)

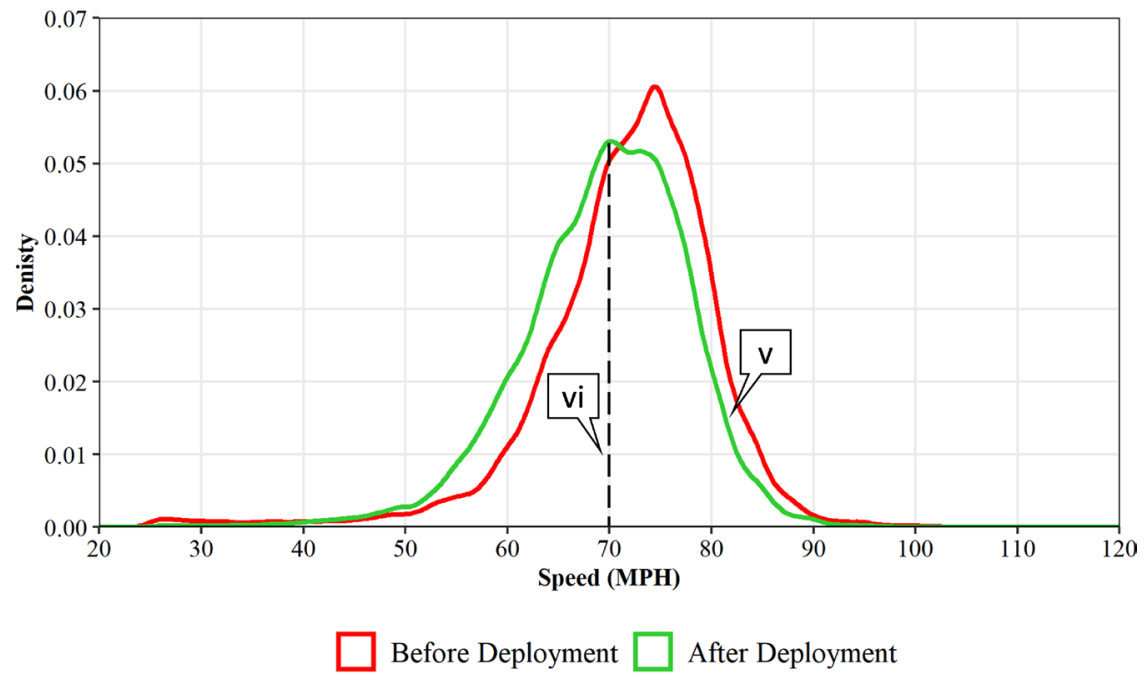

(b)

Figure 7. Distribution of speeds before and after the deployment of speed feedback display sign. (a) Spatial distribution of speeds every 0.1 -mi upstream and downstream of the sign; (b) Density plot comparing speeds on a $0.2-\mathrm{mi}(\sim 1000 \mathrm{ft})$ section before and after the sign. 
intuitive as motorists possibly react as soon as they see the signs. Speeds continue to decrease downstream of the sign, as shown by the "After" curve shifting further left. Although the speed limit in this region was $55 \mathrm{mph}$ (callout iii), the observed median speeds on both before and after sections were still around 70 $\mathrm{mph}$. The highest reduction in median speed was observed between a 0.1 to 0.2 -mi section downstream (callout iv) of the sign, with a 5 -mph reduction between the before and after deployment.

A t-test conducted on these segments also confirmed that the mean reduction in speeds near the sign was statistically significant (Table 2). The reduction in mean speeds was found to be only statistically significant from $0.2 \mathrm{mi}(\sim 1000 \mathrm{ft})$ upstream of the sign.

To understand where the shift in speeds occur, a density plot of speeds for a 0.2 -mi before and after section near the sign is plotted. The kernel density plots, which are smooth curves estimating the probability density function of the continuous variable, help compare the distributions in an effective way. The area under each curve always adds up to 1 . Figure 7 (b) compares the density plot for before and after deployments. The "After Deployment" distribution is slightly flatter and shifted to the left of the "Before Deployment" distribution, indicating a dip in speeds. The shift in the right tail also shows that the upper speeds dropped in the after period (callout v). Analyzing the area under the curve, this translates to a proportion of around $10 \%-15 \%$ reduction in sample speeds greater than $70 \mathrm{mph}$ (callout vi).

\section{Noteworthy Speed Reductions Inside Work Zone}

This spatial data also provides an opportunity to identify locations in the work zone with large speed drops. Callouts i-iii on Figure 8 (similar to Figure 6(b)) highlights some of the major speed drops. The first drop occurs around MM 144 (callout i) due to a lane shift in the geometry. This closely follows the "Lane Shift Ahead" warning sign (callout q on Figure 3 and Table 1) and ground truth images with mile markers from the work zone also confirms this geometry change (callout $\mathrm{x}$ on Figure 9(a)). The second drop happens around MM 143.8 (callout

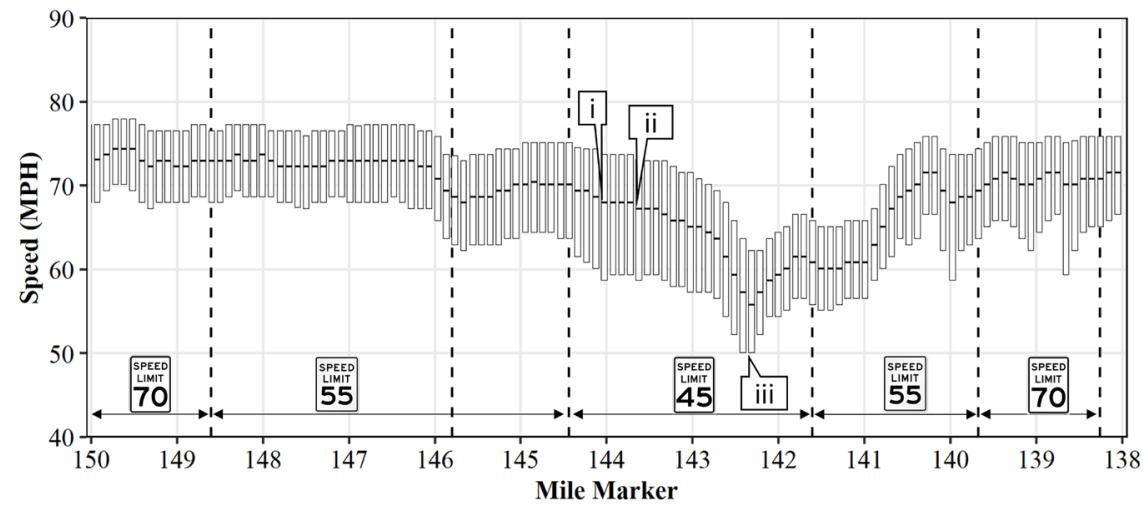

Figure 8. Identifying major speed drops inside the work zone. 
Table 2. t-test comparing mean speeds before and after the deployment of speed feedback display sign.

\begin{tabular}{|c|c|c|c|c|c|c|c|c|}
\hline \multirow[t]{2}{*}{ Mile Marker } & \multicolumn{2}{|c|}{$\begin{array}{l}\text { Sample } \\
\text { Size }\end{array}$} & \multicolumn{2}{|c|}{$\begin{array}{l}\text { Mean } \\
\text { Speed } \\
(\mathrm{MPH})\end{array}$} & \multicolumn{2}{|c|}{$\begin{array}{c}\text { Standard } \\
\text { Deviation } \\
(\mathrm{MPH})\end{array}$} & \multirow[t]{2}{*}{ p-value } & \multirow{2}{*}{$\begin{array}{c}\text { Significan } \\
\text { reduction } \\
\text { in mean } \\
\text { speeds }\end{array}$} \\
\hline & Before & After & Before & After & Before & After & & \\
\hline $147.0-146.9$ & 11,946 & 11,729 & 71.97 & 72.46 & 7.67 & 6.68 & 1.000 & - \\
\hline $146.9-146.8$ & 12,036 & 11,764 & 72.16 & 72.39 & 7.43 & 6.82 & 0.995 & - \\
\hline $146.8-146.7$ & 11,983 & 11,747 & 72.35 & 72.43 & 7.36 & 7.03 & 0.792 & - \\
\hline $146.7-146.6$ & 11,944 & 11,833 & 72.22 & 72.09 & 7.59 & 7.36 & 0.09 & - \\
\hline $146.6-146.5$ & 11,988 & 11,770 & 72.26 & 72.26 & 7.37 & 7.09 & 0.515 & - \\
\hline $146.5-146.4$ & 11,928 & 11,716 & 72.38 & 72.64 & 7.42 & 6.70 & 0.998 & - \\
\hline $146.4-146.3$ & 11,986 & 11,748 & 72.01 & 72.41 & 7.72 & 6.72 & 0.999 & - \\
\hline $146.3-146.2$ & 12,033 & 11,814 & 71.55 & 72.10 & 8.33 & 7.18 & 1.000 & - \\
\hline $146.2-146.1$ & 11,923 & 11,636 & 71.20 & 71.55 & 9.04 & 7.79 & 0.999 & - \\
\hline $146.1-146.0$ & 11,029 & 10,774 & 71.91 & 71.77 & 8.78 & 7.36 & 0.093 & - \\
\hline $146.0-145.9$ & 11,015 & 10,956 & 71.83 & 70.37 & 8.59 & 7.85 & $<0.001$ & Yes \\
\hline $145.9-145.8$ & 11,035 & 11,340 & 71.66 & 68.46 & 8.77 & 8.16 & $<0.001$ & Yes \\
\hline $145.8-145.7^{\star}$ & 11,122 & 11,380 & 71.49 & 67.70 & 8.89 & 8.26 & $<0.001$ & Yes \\
\hline $145.7-145.6$ & 11,945 & 12,147 & 70.66 & 67.27 & 9.57 & 8.59 & $<0.001$ & Yes \\
\hline $145.6-145.5$ & 11,894 & 12,062 & 70.65 & 67.64 & 9.83 & 8.76 & $<0.001$ & Yes \\
\hline $145.5-145.4$ & 12,038 & 11,988 & 69.96 & 67.32 & 10.52 & 9.29 & $<0.001$ & Yes \\
\hline $145.4-145.3$ & 12,005 & 11,925 & 69.82 & 67.39 & 10.21 & 9.41 & $<0.001$ & Yes \\
\hline $145.3-145.2$ & 11,939 & 11,842 & 70.17 & 67.72 & 9.99 & 9.51 & $<0.001$ & Yes \\
\hline $145.2-145.1$ & 11,855 & 11,667 & 70.30 & 67.92 & 10.07 & 9.61 & $<0.001$ & Yes \\
\hline $145.1-145.0$ & 11,684 & 11,546 & 70.65 & 68.38 & 9.79 & 9.46 & $<0.001$ & Yes \\
\hline
\end{tabular}

*location of speed feedback display sign.

ii), where the left shoulder is closed due to construction (callout y on Figure 9(b)). The largest speed drop around MM 142.4 (callout iii) is due to a narrow lane without both shoulders (callout y and $\mathrm{z}$ on Figure 9(c)) on the Prairie Creek bridge. It is interesting to note that the larger speed reductions are not due to speed limit regulations, but due to geometry changes that require additional driver workloads, especially during shoulder drops and lane shifts. 


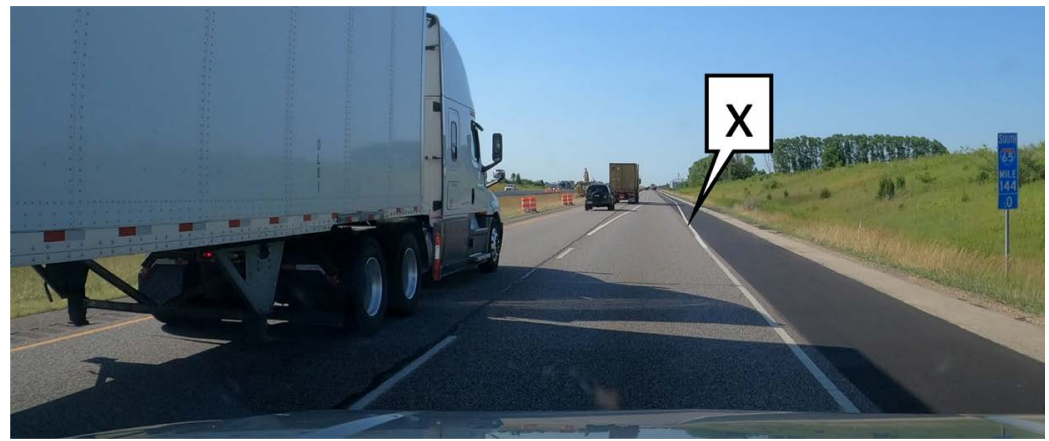

(a)

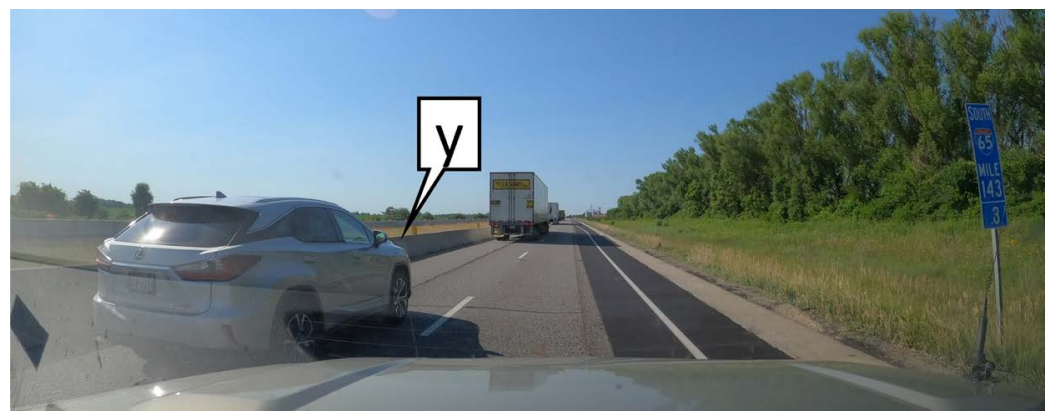

(b)

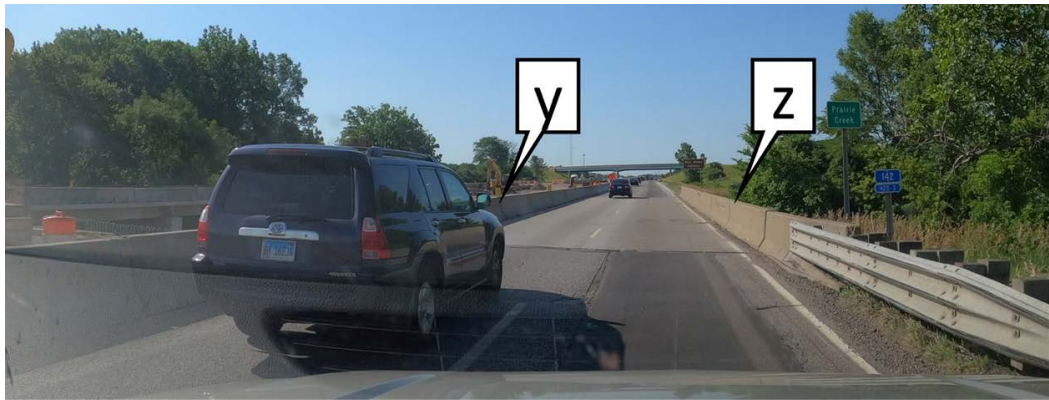

(c)

Figure 9. Images corresponding to callouts in Figure 9 with speed drops. (Callout $x$ shows the lane shift; callout y shows the left shoulder closed; callout $\mathrm{z}$ shows right shoulder closed). (a) Lane shift (callout i on Figure 9); (b) Left shoulder closed (callout ii on Figure 9); (c) Narrow lane bridge with no shoulders (callout iii on Figure 9).

\section{Conclusions}

High speeds in construction zones are a well-documented risk factor that increases the frequency and severity of crashes. This study analyzed over 27,000 anonymous connected vehicle trajectories to evaluate the impact on vehicle speed of the following work zone features:

- Regulatory speed limit signs;

- Speed feedback displays;

- Work zone features such as the change in shoulder width and lane shifts.

Spatial analysis over a 0.2-mi segment before and after the posted speed limit signs over a one-week period showed that the signs had no impact on reducing speeds (Figure 5). 
A one-week before/after analysis was also conducted to study the impact of a radar-based speed feedback display with a regulatory speed limit sign. Interquartile range plots showed a significant speed reduction beginning approximately $1000 \mathrm{ft}$ upstream of the radar speed sign (Figure 6) and density plots showed that the upper extreme speeds ( $15 \mathrm{mph}$ above the speed limit) in this region dropped by $10 \%-15 \%$ (Figure 7(b)). The maximum drop in speeds occurred at $1000 \mathrm{ft}$ downstream of the sign (median drop of $5 \mathrm{mph}$ ) and overall results were found to be statistically significant (Table 2).

The analysis also revealed that the larger speed drops inside the work zone were due to geometric constraints that required additional driver workloads, especially during shoulder drops and lane shifts (Figure 8). Speeds were found to be the lowest when there were no shoulders on both sides (Figure 9(c)).

Results from this study show that the most substantial reduction in speeds occurred during two cases-when shoulder widths were reduced and/or lane shifts occurred. Even though multiple speed limit signs and reduced speed ahead warnings were placed throughout the work zone (Table 1), this had little to no impact on motorist speed. However, speeds were found to increase when normal speed limit conditions resumed.

Although this paper focused on using connected vehicle data to assess the temporal and spatial impact of speed feedback displays, the connected vehicle data was also valuable for identifying other features of the work zone that had (or did not have) statistically significant impacts on speed. As agencies continue to explore new work zone management techniques, the connected vehicle data processing techniques described in this paper can be readily adapted to evaluating other concepts such as variable message signs, arrow board placement, rumble strips, alternative pavement markings, alternative shoulder widths, and perhaps in vehicle messaging/feedback.

\section{Acknowledgements}

Data used in this study was provided by Wejo Data Services Inc. This work was supported by the Joint Transportation Research Program administered by the Indiana Department of Transportation and Purdue University. The contents of this paper reflect the views of the authors, who are responsible for the facts and the accuracy of the data presented herein, and do not necessarily reflect the official views or policies of the sponsoring organizations. These contents do not constitute a standard, specification, or regulation.

\section{Conflicts of Interest}

The authors declare no conflicts of interest regarding the publication of this paper.

\section{References}

[1] National Work Zone Safety Information Clearinghouse (2019) Work Zone Fatal 
Crashes and Fatalities.

https://www.workzonesafety.org/crash-information/work-zone-fatal-crashes-fataliti es/\#national

[2] The National Institute for Occupational Safety and Health (2019) Highway Work Zone Safety. https://www.cdc.gov/niosh/topics/highwayworkzones/default.html

[3] Cirillo, J.A. (1968) Interstate System Accident Research Study II, Interim Report II. Public Roads, 35, 71-75. https://trid.trb.org/view/107635

[4] Pigman, J.G. and Agent, K.R. (1988) Analysis of Accidents in Construction and Maintenance Work Zones. Kentucky Transportation Center, Lexington, Report No. UKTRP-88-13, 20-27. https://uknowledge.uky.edu/ktc_researchreports/514/

[5] Garber, N.J. and Gadiraju, R. (1989) Factors Affecting Speed Variance and Its Influence on Accidents. Transportation Research Record, No. 1213, 64-71. http://onlinepubs.trb.org/Onlinepubs/trr/1989/1213/1213-009.pdf

[6] Richards, S.H., Wunderlich, R.C. and Dudek, C.L. (1985) Field Evaluation of Work Zone Speed Control Techniques. Transportation Research Record, No. 1035, 66-78.

[7] Brewer, M.A., Pesti, G. and Schneider, W.H. (2005) Identification and Testing of Measures to Improve Work Zone Speed Limit Compliance. Texas Transportation Institute, Texas A \& M University System, FHWA/TX-06/0-4707-1. https://static.tti.tamu.edu/tti.tamu.edu/documents/0-4707-1.pdf

[8] Brewer, M.A., Pesti, G. and Schneider, W. (2006) Improving Compliance with Work Zone Speed Limits: Effectiveness of Selected Devices. Transportation Research Record: Journal of the Transportation Research Board, 1948, 67-76. https://doi.org/10.1177\%2F0361198106194800108

[9] Banerjee, S., Jeihani, M. and Khadem, N.K. (2019) Influence of Work Zone Signage on Driver Speeding Behavior. Journal of Modern Transportation, 27, 52-60. https://doi.org/10.1007/s40534-019-0182-5

[10] Fudala, N.J. and Fontaine, M.D. (2010) Work Zone Variable Speed Limit Systems: Effectiveness and System Design Issues. Virginia Transportation Research Council, Charlottesville, No. FHWA/VTRC 10-R20. https://www.virginiadot.org/vtrc/main/online_reports/pdf/10-r20.pdf

[11] Lyles, R.W., Taylor, W.C., Lavansiri, D. and Grossklaus, J. (2004) A Field Test and Evaluation of Variable Speed Limits in Work Zones. Transp. Transportation Research Board 83rd Annual Meeting, Washington DC, 11-15 January 2004, 1-21. http://sp.stsmo.transportation.org/Documents/TRB2004-001180.pdf

[12] Ullman, G.L., Barricklow, P.A., Arredondo, R., Rose, E.R. and Fontaine, M.D. (2002) Traffic Management and Enforcement Tools to Improve Work Zone Safety. Texas Transportation Institute, Texas A \& M University System, FHWA/TX-03/2137-3.

[13] Pesti, G., Jessen, D.R., Byrd, P.S. and McCoy, P.T. (1999) Traffic Flow Characteristics of the Late Merge Work Zone Control Strategy. Transportation Research Record, 1657, 1-9. https://doi.org/10.3141\%2F1657-01

[14] Bham, G.H. and Mohammadi, M.A. (2011) Evaluation of Work Zone Speed Limits: An Objective and Subjective Analysis of Work Zones in Missouri. Mid-America Transportation Center, Lincoln, MATC Report \#25-1121-0001-119. https://rosap.ntl.bts.gov/view/dot/24680

[15] Wang, C., Dixon, K.K. and Jared, D. (2003) Evaluating Speed-Reduction Strategies for Highway Work Zones. Transportation Research Record, 1824, 44-53. https://doi.org/10.3141\%2F1824-06

[16] Mattox, J.H., Sarasua, W.A., Ogle, J.H., Eckenrode, R.T. and Dunning, A (2007) 
Development and Evaluation of Speed-Activated Sign to Reduce Speeds in Work Zones. Transportation Research Record, 2015, 3-11. https://doi.org/10.3141\%2F2015-01

[17] Joerger, M. (2010) Photo Radar Speed Enforcement in A State Highway Work Zone: Demonstration Project on Yeon Avenue and on Powell Boulevard in Portland, Oregon. Oregon Department of Transportation, Salem, Report No. SR 500-390.

https://www.oregon.gov/ODOT/Programs/ResearchDocuments/PhotoRadar_Speed .pdf

[18] Benekohal, R.F., Chitturi, M.V., Hajbabaie, A., Wang, M.H. and Medina, J.C. (2008) Automated Speed Photo Enforcement Effects on Speeds in Work Zones. Transportation Research Record, 2055, 11-20. https://doi.org/10.3141\%2F2055-02

[19] Benekohal, R.F., Wang, M.H., Chitturi, M.V., Hajbabaie, A. and Medina, J.C. (2009) Speed Photo-Radar Enforcement and Its Effects on Speed in Work Zones. Transportation Research Record, 2096, 89-97. https://doi.org/10.3141\%2F2096-12

[20] Horowitz, A.J. and Notbohm, T. (2005) Testing Temporary Work Zone Rumble Strips. Midwest Smart Work Zone Deployment Initiative, Mid-America Transportation Center, Lincoln, Nebraska.

https://intrans.iastate.edu/app/uploads/2018/08/MwSWZDI-2005-Horowitz-Tempo rary_Rumble_Strips.pdf

[21] Savolainen, P.T., Reddy, V., Santos, P., Joseph, B. and Datta, T.K. (1970) Evaluation of Temporary Removable Rumble Strips for Speed Reduction. Transportation Research Board 88th Annual Meeting, Washington DC, 11-15 January 2009. http://pubsindex.trb.org/view.aspx?id=881475

[22] Fontaine, M.D. and Carlson, P.J. (2001) Evaluation of Speed Displays and Rumble Strips at Rural-Maintenance Work Zones. Transportation Research Record, 1745, 27-38. https://doi.org/10.3141\%2F1745-04

[23] Noel, E.C., Dudek, C.L., Pendleton, O.J. and Sabra, Z.A. (1988) Speed Control through Freeway Work Zones: Techniques Evaluation. Transportation Research Record, No. 1163, 31-42.

[24] Zech, W.C., Mohan, S. and Dmochowski, J. (2005) Evaluation of Rumble Strips and Police Presence as Speed Control Measures in Highway Work Zones. Practice Periodical on Structural Design and Construction, 10, 267-275. https://doi.org/10.1061/(ASCE)1084-0680(2005)10:4(267)

[25] Ravani, B. and Wang, C. (2018) Speeding in Highway Work Zone: An Evaluation of Methods of Speed Control. Accident Analysis \& Prevention, 113, 202-212. https://doi.org/10.1016/j.aap.2018.01.030

[26] McCoy, P.T., Bonneson, J.A. and Kollbaum, J.A. (1995) Speed Reduction Effects of Speed Monitoring Displays with Radar in Work Zones on Interstate Highways. Transportation Research Record, 1509, 65-72.

[27] Pesti, G. and McCoy, P.T (2001) Long-Term Effectiveness of Speed Monitoring Displays in Work Zones on Rural Interstate Highways. Transportation Research Record, 1754, 21-30. https://doi.org/10.3141\%2F1754-03

[28] Chitturi, M.V. and Benekohal, R.F. (2006) Effect of Speed Feedback Device on Speeds in Interstate Highway Work Zones. Applications of Advanced Technology in Transportation-Proceedings of the 9 th International Conference on Applications of Advanced Technology in Transportation, Chicago, August 13-16 2006, 629-634. https://doi.org/10.1061/40799(213)100

[29] Ardeshiri, A. and Jeihani, M. (2014) A Speed Limit Compliance Model for Dynamic Speed Display Sign. Journal of Safety Research, 51, 33-40. 
https://doi.org/10.1016/j.jsr.2014.08.001

[30] Remias, S.M., Mekker, M., McNamara, M., Sturdevant, J.R., Cox, E.D. and Bullock, D.M. (2015) Assessment of Speed Limit Locations Using Crowd Sourced Probe Vehicle Data. Transportation Research Record, 2484, 10-22. https://doi.org/10.3141\%2F2484-02

[31] Wasson, J.S., Boruff, G.W., Hainen, A.M., Remias, S.M., Hulme, E.A., Farnsworth, G.D., et al. (2011) Evaluation of Spatial and Temporal Speed Limit Compliance in Highway Work Zones. Transportation Research Record: Journal of the Transportation Research Board, 2258, 1-15. https://doi.org/10.3141\%2F2258-01

[32] Mathew, J.K., Desai, J.C., Sakhare, R.S., Kim, W., Li, H. and Bullock, D.M. (2021) Big Data Applications for Managing Roadways. ITE Journal, 91, 28-35.

https://www.nxtbook.com/ygsreprints/ITE/ite-journal-february-2021/index.php\#/p $\underline{128}$

[33] Hunter, M., Mathew, J.K., Cox, E., Blackwell, M. and Bullock, D.M. (2021) Estimation of Connected Vehicle Penetration Rate on Indiana Roadways. JTRP Affiliated Reports, Paper No. 37. https://doi.org/10.5703/1288284317343 